\title{
UNCERTAINTY OF THE MEASUREMENT OF DC CONDUCTIVITY OF CERAMICS AT ELEVATED TEMPERATURES
}

\author{
Igor Štubňa - Viera Trnovcová - Libor Vozár — Štefan Csáki
}

\begin{abstract}
The electrical DC conductivity is measured at room and elevated temperatures on green ceramic samples prepared from kaolin. The arrangement of the sample, with two platinum wire electrodes inserted in the kaolin prism that was used is suitable for measurements of temperature dependences of the DC conductivity from $20^{\circ} \mathrm{C}$ to $1100^{\circ} \mathrm{C}$ in the air. The uncertainty analysis taking into account thermal expansion of the sample, homogeneity of the temperature field, measurement regime, corrosion of the electrodes, and overlapping of the electrodes is done for $1000^{\circ} \mathrm{C}$. Uncertainties connected with current and voltage measurements and uncertainties connected with the instruments that were used are also considered. The sum of all the partial uncertainties gives an expanded uncertainty of the conductivity measurement. The uncertainty varies with temperature and reaches the value of $\sim 6.5 \%$ at $1000^{\circ} \mathrm{C}$.
\end{abstract}

K e y w or d s: conductivity, temperature dependences of conductivity, uncertainty

\section{INTRODUCTION}

Properties of ceramics are evaluated mainly from mechanical point of view, ie the dominant parameters are mechanical strength and elastic moduli. Very often thermophysical properties, such as thermal conductivity and thermal volume expansion, are important for engineering applications. Electrical properties are important for some kinds of ceramics which are used in electrical equipment and power transmission lines. In these cases, the DC and $\mathrm{AC}$ conductivities are the most important properties. In ceramic research, they represent important parameters that characterize ceramic materials. The ceramic materials and their components are experimentally studied using thermal analyses, eg DTA, TGA, thermodilatometry and others. Thermoelectrometry, namely the temperature dependence of the electrical conductivity, of ceramics gives interesting and useful information about thermal behavior of ceramic materials, both green and fired [1-8]. Therefore, measurements of the DC and/or AC electrical conductivity of clay ceramics in a broad temperature range are suitable additional analyses.

An important component of electro-porcelains is kaolin; therefore our measurements and uncertainty analysis are done with this clay. The simplest arrangement of the electrodes and sample is based on two planar electrodes with the sample between them. To achieve a good contact between the green sample and electrodes, the sample is covered with a graphite suspension and platinum electrodes are pressed to the sample with a spring [1-3]. If a measurement is performed in the air, the graphite layer oxidizes at higher temperatures and a reliable measurement is not possible beyond $\sim 450-500{ }^{\circ} \mathrm{C}$. This system requires a vacuum or inert gas for measuring at higher temperatures. Some techniques, which deposit platinum electrodes directly on a ceramic sample, are developed [9], but they require too high temperatures for deposition of platinum. It is not admissible for green clay-based samples because they would be significantly changed before the measurement.

The goal of the paper is an experimental determination of the DC conductivity of green samples prepared from kaolin, up to elevated temperatures. A description of the experimental arrangement and an uncertainty analysis are also given.

\section{SAMPLE PREPARATION AND EXPERIMENTAL ARRANGEMENT}

The samples were made from kaolin which was sieved and mixed with distilled water to obtain a plastic mass with a water content of $\sim 20 \mathrm{wt} \%$. The plastic mass was pressed in a template with electrodes that were placed in the central plane of the sample. The sample has a prismatic form $10 \times 10 \times 20 \mathrm{~mm}$ and two platinum wires $(\varnothing 0.5 \mathrm{~mm})$ serve as electrodes. The distance between them is $a=3 \mathrm{~mm}$, and their overlapping is $b=15 \mathrm{~mm}$ (Fig. 1). Such an arrangement is chosen in order to minimize the surface electric current of the sample. Contact between the electrodes and clay-based sample is protected from the air, so the measurement is possible at elevated temperatures. It allows to study of these samples in a temperature interval $20^{\circ} \mathrm{C}-1100^{\circ} \mathrm{C}$, where the most important processes take place (the release of the physically bound water, dehydroxylation, sintering and a creation of the spinel/mullite structure). The samples were dried in the open air for 4 days and contained $\sim 1.5 \mathrm{wt} \%$ of the physically bound water.

* Department of Physics, Constantine the Philosopher University, A. Hlinku 1, 94974 Nitra, Slovakia; istubna@ukf.sk 


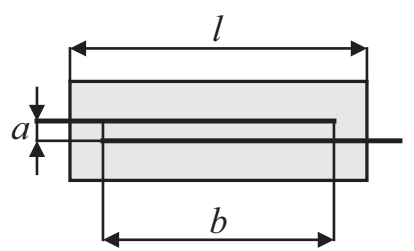

Fig. 1. The sample with electrodes, the view on the central section

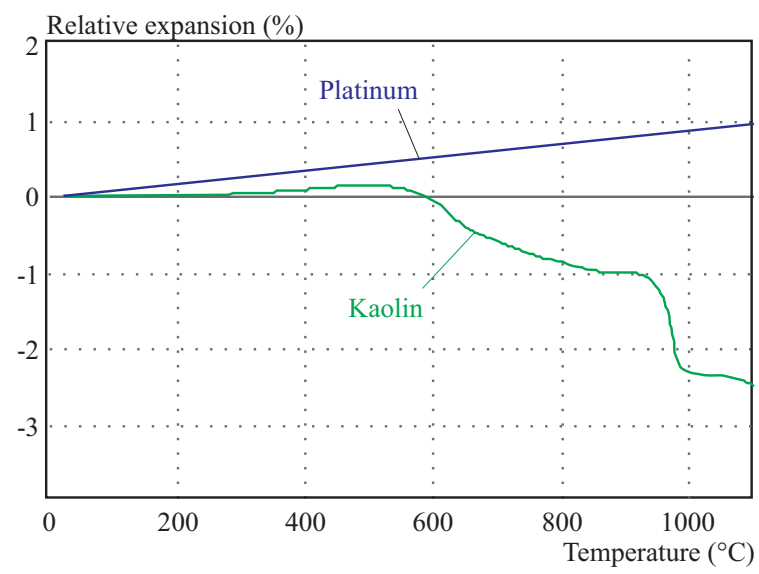

Fig. 2. Thermodilatometric curve of kaolin and platinum

The sample arrangement (Fig. 1) gives a good electrical contact between the measured material (kaolin in this case) and platinum electrodes. We used data of the linear thermal expansion of $\mathrm{Pt}$ from $20^{\circ} \mathrm{C}$ to $1100^{\circ} \mathrm{C}$ published in [10]. The thermal expansion of $\mathrm{Pt}$ is higher than that of kaolin in the temperature range when both materials thermally expand $\left(20^{\circ} \mathrm{C}-550^{\circ} \mathrm{C}\right)$; after dehydroxylation, ie above $500{ }^{\circ} \mathrm{C}$, newly developed metakaolin contracts (Fig. 2). There is an intensive contraction of the kaolin sample above $\sim 950^{\circ} \mathrm{C}$ from a collapse of the metakaolinit structure and its transformation into Al-Si spinel and mullite $[11,12]$. Therefore, the contact between the Pt electrodes and kaolin/metakaolin/spinel/mullite is reliable over the used temperature range $20-1100^{\circ} \mathrm{C}$.

To measure the sample resistance, we apply a voltampere method, where an electrometer Keithley 6514 is used for measuring and recording the current. The measuring circuit — which represents a serial connection of the power supply, the sample, and the electrometer $[9,13]$ - is fed with the DC power supply Tesla BS 525 with a voltage of $4.83 \mathrm{~V}$ (Fig. 3). According to the instruction manual for the Keithley 6541 Electrometer, a voltage burden is less than $100 \mu \mathrm{V}$ for the used current ranges $20 \mu \mathrm{A}-20 \mathrm{pA}$, so we take $U$ equal to the voltage of the power supply.

The sample is located in a horizontal furnace heated by silicon carbide rods that are connected, through a power block, to the temperature programmer Grubatec TLK 48. The temperature is measured by a Pt-PtRh10 thermocouple. The heating rate is $2-10^{\circ} \mathrm{C} / \mathrm{min}$ and the ambient atmosphere is the air.

To avoid an influence of the AC heating current on the small DC current measured using the electrometer, the measuring period is divided into a time interval of $16 \mathrm{~s}$, during which the heating current is switched on, and a time interval of $4 \mathrm{~s}$ when the furnace is switched off using a double-contact electromechanical relay. During these $4 \mathrm{~s}$, the DC current is measured. Thus the DC current is recorded every $20 \mathrm{~s}$.

We calculated the DC conductivity using the relation

$$
\sigma=\beta \frac{I}{U}
$$

where $U$ is a voltage drop on the sample and $I$ is the current measured with the electrometer. The numerical value $\beta=12.85 \mathrm{~m}^{-1}$ is a geometrical factor that is experimentally determined by a comparison of the DC conductivity measured with the help of two parallel planar electrodes and the conductivity measured on the sample according to Fig. 1 [14].

\section{UNCERTAINTY ANALYSIS}

According to [16], uncertainty of measurements consists of components from two main categories: A and B. Type A components of the complete uncertainty are evaluated statistically. The uncertainty of the measured quantity $x_{i}$ is

$$
u_{A}\left(x_{i}\right)=\frac{s_{i}}{\sqrt{n}}
$$

where $s_{i}$ is the standard deviation and $n$ is a number of independent measurements.

The uncertainties of the type $\mathrm{B}, u_{B}\left(x_{i}\right)$, are calculated from the manufacturer's information, calibration certificates, or expert's estimation. Sources of these uncertainties are different, for example inhomogeneity of temperature field, thermal expansion and others. All these disturbances are sources of the uncertainties that do not submit to statistical treatment. These uncertainties can be divided in two groups. In the first group are uncertainties $u_{B}\left(x_{i}\right)=M A E / \sqrt{3}$ which come from the digital measurers we used, where MAE is a maximum admissible error. The second group reflects the uncertainties of another origin that influence the value of the conductivity. These uncertainties must be evaluated individually.

\subsection{Uncertainty analysis of the geometrical fac- tor}

As noted above, the geometrical factor $\beta$ in (1) was determined experimentally, so we had to know its uncertainty. We performed the uncertainty analysis on 5 samples with planar electrodes and on 5 samples made according to Fig. 1. The samples were prepared to be as identical as possible and the same material was used.

A resistance of the sample with the planar electrodes is

$$
R_{1}=\frac{1}{\sigma} \frac{d}{S}
$$

In (3) $\sigma$ is conductivity, $d$ is distance between the planar electrodes and $S$ is area the of the electrode. 
Table 1. The mean value $\langle x\rangle$, standard deviation $s$ and standard uncertainty of the A-type $u_{A}(x)$

\begin{tabular}{c|ccccccc}
\hline & $d / \mathrm{m}$ & $c_{1} / \mathrm{m}$ & $c_{2} / \mathrm{m}$ & $U_{1} / \mathrm{V}$ & $I_{1} / \mathrm{A}$ & $U_{2} / \mathrm{V}$ & $I_{2} / \mathrm{A}$ \\
\hline$\langle x\rangle$ & $7.06 \times 10^{-3}$ & $1.33 \times 10^{-2}$ & $2.16 \times 10^{-2}$ & 6.07 & $4.40 \times 10^{-3}$ & 5.97 & $8.26 \times 10^{-3}$ \\
$s$ & $1.34 \times 10^{-4}$ & $3.13 \times 10^{-5}$ & $3.00 \times 10^{-5}$ & $9.57 \times 10^{-3}$ & $1.43 \times 10^{-4}$ & $1.12 \times 10^{-2}$ & $2.06 \times 10^{-4}$ \\
$u_{A}(x)$ & $5.99 \times 10^{-5}$ & $1.40 \times 10^{-5}$ & $1.34 \times 10^{-5}$ & $4.28 \times 10^{-3}$ & $6.40 \times 10^{-5}$ & $5.00 \times 10^{-3}$ & $9.21 \times 10^{-5}$ \\
\hline
\end{tabular}

Table 2. List of uncertainties for geometrical factor

\begin{tabular}{|c|c|c|c|c|c|}
\hline & $\begin{array}{l}\text { Uncertainity } \\
\text { source }\end{array}$ & Type & $\begin{array}{l}\text { sensitivity } \\
\text { coefficient } A\end{array}$ & $\begin{array}{l}\text { standard } \\
\text { uncertainity } u(x)\end{array}$ & $\begin{array}{l}A(x) u(x) \\
\left(\mathrm{m}^{-1}\right)\end{array}$ \\
\hline 1 & Repeatibility of $d$ & $\mathrm{~A}$ & $1780 \mathrm{~m}^{-2}$ & $5.99 \times 10^{-5} \mathrm{~m}$ & 0.11 \\
\hline 2 & Repeatibility of $c_{1}$ & $\mathrm{~A}$ & $945 \mathrm{~m}^{-2}$ & $1.40 \times 10^{-5} \mathrm{~m}$ & $-1.32 \times 10^{-2}$ \\
\hline 3 & Repeatibility of $c_{2}$ & A & $-582 \mathrm{~m}^{-2}$ & $1.34 \times 10^{-5} \mathrm{~m}$ & $-7.80 \times 10^{-3}$ \\
\hline 4 & Repeatibility of $U_{1}$ & $\mathrm{~A}$ & $-2.07 \mathrm{~m}^{-1} \mathrm{~V}^{-1}$ & $4.28 \times 10^{-3} \mathrm{~V}$ & $-8.86 \times 10^{-3}$ \\
\hline 5 & Repeatibility of $U_{2}$ & $\mathrm{~A}$ & $2.10 \mathrm{~m}^{-1} \mathrm{~V}^{-1}$ & $5.00 \times 10^{-3} \mathrm{~V}$ & $1.05 \times 10^{-2}$ \\
\hline 6 & Repeatibility of $I_{1}$ & $\mathrm{~A}$ & $2856 \mathrm{~m}^{-1} \mathrm{~A}^{-1}$ & $6.40 \times 10^{-5} \mathrm{~A}$ & 0.183 \\
\hline 6 & Repeatibility of $I_{2}$ & $\mathrm{~A}$ & $-1522 \mathrm{~m}^{-1} \mathrm{~A}^{-1}$ & $9.21 \times 10^{-5} \mathrm{~A}$ & -0.140 \\
\hline \multicolumn{5}{|c|}{ The sum of the A-type uncertainties, (14) } & 0.256 \\
\hline 7 & $\begin{array}{l}\text { A-meter, } M A E=1 \times 10^{-5} \mathrm{~m} \\
u_{B}(d)=1 \times 10^{-5} / \sqrt{3}\end{array}$ & B & $1780 \mathrm{~m}^{-2}$ & $5.77 \times 10^{-5} \mathrm{~m}$ & 0.103 \\
\hline 8 & $\begin{array}{l}\text { A-meter, } M A E=1 \times 10^{-5} \mathrm{~m} \\
u_{B}\left(c_{1}\right)=1 \times 10^{-5} / \sqrt{3}\end{array}$ & B & $-945 \mathrm{~m}^{-2}$ & $5.77 \times 10^{-5} \mathrm{~m}$ & $-5.45 \times 10^{-2}$ \\
\hline 9 & $\begin{array}{l}\text { Caliper, } M A E=1 \times 10^{-5} \mathrm{~m} \\
u_{B}\left(c_{2}\right)=1 \times 10^{-5} / \sqrt{3}\end{array}$ & $\mathrm{~B}$ & $-582 \mathrm{~m}^{-2}$ & $5.77 \times 10^{-5} \mathrm{~m}$ & $-3.36 \times 10^{-2}$ \\
\hline 10 & $\sqrt{2 A\left(c_{1}\right) A\left(c_{2}\right) u_{B}\left(c_{1}\right) u_{B}\left(c_{2}\right)}$ & B & - & - & $6.05 \times 10^{-2}$ \\
\hline 11 & $\begin{array}{l}\text { V-meter, } M A E=1 \times 10^{-5} \mathrm{~V} \\
u_{B}\left(U_{1}\right)=1 \times 10^{-5} / \sqrt{3}\end{array}$ & $\mathrm{~B}$ & $-2.07 \mathrm{~m}^{-1} \mathrm{~V}^{-1}$ & $5.77 \times 10^{-5} \mathrm{~V}$ & $-1.19 \times 10^{-4}$ \\
\hline 12 & $\begin{array}{l}\text { V-meter, } M A E=1 \times 10^{-5} \mathrm{~m} \\
u_{B}\left(U_{2}\right)=1 \times 10^{-5} / \sqrt{3}\end{array}$ & $\mathrm{~B}$ & $2.10 \mathrm{~m}^{-1} \mathrm{~V}^{-1}$ & $5.77 \times 10^{-5} \mathrm{~V}$ & $1.21 \times 10^{-4}$ \\
\hline 13 & $\begin{array}{l}\text { Caliper, } M A E=1 \times 10^{-8} \mathrm{~m} \\
u_{B}\left(I_{1}\right)=1 \times 10^{-8} / \sqrt{3}\end{array}$ & $\mathrm{~B}$ & $2856 \mathrm{~m}^{-1} \mathrm{~A}^{-1}$ & $5.77 \times 10^{-8} \mathrm{~m}$ & $1.65 \times 10^{-4}$ \\
\hline 14 & $\begin{array}{l}\text { Caliper, } M A E=1 \times 10^{-8} \mathrm{~m} \\
u_{B}\left(I_{2}\right)=1 \times 10^{-8} / \sqrt{3}\end{array}$ & $\mathrm{~B}$ & $-1522 \mathrm{~m}^{-1} \mathrm{~A}^{-1}$ & $5.77 \times 10^{-8} \mathrm{~m}$ & $-8.78 \times 10^{-5}$ \\
\hline \multicolumn{5}{|c|}{ The sum of the B-type uncertainties, (15) } & 0.135 \\
\hline \multicolumn{5}{|c|}{ The combined uncertainty, (16) } & 0.290 \\
\hline \multicolumn{5}{|c|}{ The expanded uncertainty } & 0.580 \\
\hline
\end{tabular}

The resistance of the sample with the wire electrodes (Fig. 1) can be written as

$$
R_{2}=\frac{1}{\sigma} \beta,
$$

where $\beta$ is a function of dimensions of the sample, quantities $a$ and $b$, which are visible in Fig. 1, as well as of the radius of the wires. The value of $\beta$ must be experimentally derived from the results of both types of measurements on the same material. If the dimensions of the sample as well as the location of the wires are the same for every sample, the geometrical factor becomes a numerical constant.

The resistancies $R_{1}$ and $R_{2}$ were measured with V-A method using an RC oscillator Hameg HM 8030-6, digital multimeter Hameg HM 8012 as a voltmeter, and digital multimeter Fluke 289 as an ammeter. We used an AC current with a frequency $50 \mathrm{~Hz}$ to avoid electrolysis phenomena on the electrodes. The resistances are $R_{1}=U_{1} / I_{1}$ and $R_{2}=U_{2} / I_{2}$, where $I_{1}$ is the current through the sample with the planar electrodes, $U_{1}$ is a voltage on the sample with the planar electrodes, $I_{2}$ is current through the sample in Fig. 1, and $U_{1}$ is voltage on the sample in Fig. 1. Substituting these relations into Eqs. (3) and (4), we obtain

$$
\beta=\frac{U_{2} I_{1}}{U_{1} I_{2}} \frac{d}{c_{1} c_{2}},
$$

where $S=c_{1} c_{2}$ is area of the rectangular electrodes. All quantities on the right side of (5) are directly measured. Their mean values, standard deviations and uncertainties are given in Tab. 1.

We determine the sensitivity coefficients $A\left(x_{i}\right)$ as partial derivations of (5), for example

$$
\begin{aligned}
& A\left(U_{2}\right)=\frac{\partial \beta}{\partial U_{2}}=\frac{I_{1}}{U_{1} I_{2}} \frac{d}{c_{1} c_{2}} \\
& A\left(U_{1}\right)=\frac{\partial \beta}{\partial U_{1}}=-\frac{U_{2} I_{1}}{U_{1}^{2} I_{2}} \frac{d}{c_{1} c_{2}},
\end{aligned}
$$

and so on. 


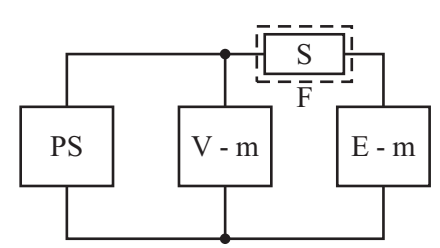

Fig. 3. A basic scheme of the DC conductivity measurement. PS DC stabilized power supply, V-m - voltmeter, E-m - electrometer, $\mathrm{S}$ - sample, $\mathrm{F}$ - furnace

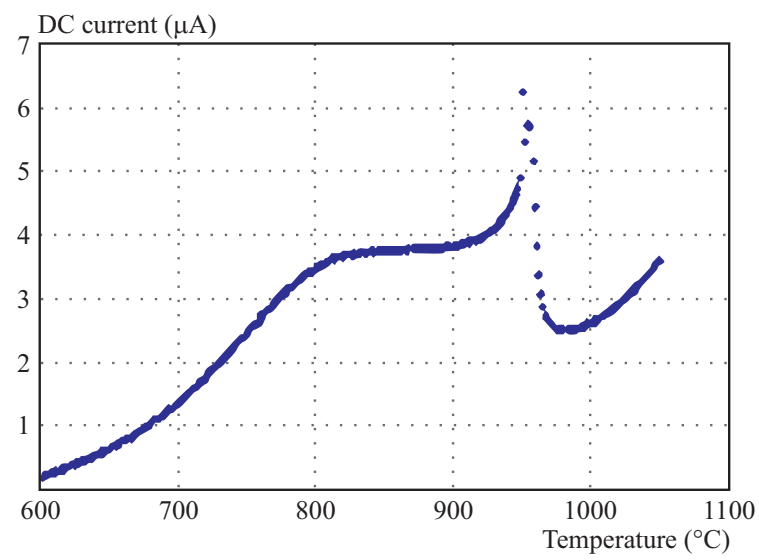

Fig. 4. Temperature dependence of the DC current

Table 3. The mean values, standard deviations and standard uncertainties at room temperature

\begin{tabular}{ccc}
\hline & $I / \mathrm{mA}$ & $U / \mathrm{V}$ \\
\hline$\langle X\rangle$ & 1.56 & 4.82 \\
$s$ & 0.06 & 0 \\
$u_{A}(x)$ & 0.03 & 0 \\
\hline
\end{tabular}

We obtain their numerical values by substituting the mean values of the measured quantities (Tab. 1) into equations for the sensitivity coefficients. They are shown in Tab. 2.

The sum of the A-type uncertainties is given by

$$
\begin{gathered}
u_{A}(\beta)=\left(A^{2}(d) u_{A}^{2}(d)+A^{2}\left(c_{1}\right) u_{A}^{2}\left(c_{1}\right)+A^{2}\left(c_{2}\right) u_{A}^{2}\left(c_{2}\right)+\right. \\
A^{2}\left(U_{1}\right) u_{A}^{2}\left(U_{1}\right)+A^{2}\left(U_{2}\right) u_{A}^{2}\left(U_{2}\right)+A^{2}\left(I_{1}\right) u_{A}^{2}\left(I_{1}\right) \\
\left.+A^{2}\left(I_{2}\right) u_{A}^{2}\left(I_{2}\right)\right)^{1 / 2}
\end{gathered}
$$

In addition to the B-type uncertainties, which are connected with measurers (lines $7-14$ in Tab. 2), some other possible influences can be taken into account. We only have one possible source of such uncertainty - the overlapping of the electrodes. The sample is designed with the overlapping of the wire electrodes $b=15 \mathrm{~mm}$, Fig. 1 . We have experimentally found that a deviation of the overlapping in the range between 14 and $20 \mathrm{~mm}$ does not lead to a change of the current. Therefore, an inaccuracy $\pm 0.5 \mathrm{~mm}$ in adjustment of $b$, which is easy to reach, does not influence the current.
The area of the planar electrodes is measured by the same caliper and calculated as $S=c_{1} c_{2}$, where $c_{1}$ and $c_{2}$ are the sides of the rectangular electrodes. According to [16], term $u_{B}(S)=\sqrt{2 r A\left(c_{1}\right) A\left(c_{2}\right) u_{B}\left(c_{1}\right) u_{B}\left(c_{2}\right)}$, where we put $r= \pm 1$, must be added to the budget of the B-type uncertainties, see Tab. 2.

The sum of the B-type uncertainties is given by equation

$$
\begin{gathered}
u_{B}(\beta)=\left(A^{2}(d) u_{B}^{2}(d)+A^{2}\left(c_{1}\right) u_{B}^{2}\left(c_{1}\right)+A^{2}\left(c_{2}\right) u_{B}^{2}\left(c_{2}\right)+\right. \\
2 A\left(c_{1}\right) A\left(c_{2}\right) u_{B}\left(c_{1}\right) u_{B}\left(c_{2}\right)+A^{2}\left(U_{1}\right) u_{B}^{2}\left(U_{1}\right)+ \\
\left.A^{2}\left(U_{2}\right) u_{B}^{2}\left(U_{2}\right)+A^{2}\left(I_{1}\right) u_{B}^{2}\left(I_{1}\right)+A^{2}\left(I_{2}\right) u_{B}^{2}\left(I_{2}\right)\right)^{1 / 2} \cdot
\end{gathered}
$$

As follows from Tab. 2, the A-type uncertainties, mainly for a measurement of the currents, represent the main part of the uncertainty. The currents are significantly dependent on the pressure of the electrodes on the clay sample. Besides that, the current increases in time and reaches a stable value after $1 \mathrm{~min}$. Therefore, we put a weight of $200 \mathrm{~g}$ on the upper planar electrode and read the current after $1 \mathrm{~min}$.

The combined uncertainty is defined as the square root of the sum of all squared uncertainties

$$
u_{c}(\beta)=\sqrt{u_{A}^{2}(\beta)+u_{B}^{2}(\beta)} .
$$

The expanded uncertainty is the combined uncertainty $u_{c}$ multiplied by a covering factor that is usually 2 . It means that the true value is presumably within the interval $\langle\beta\rangle \pm 2 u_{c}(\beta)$ with $95 \%$ probability. The result of the uncertainty analysis for the geometrical factor is written as

$$
\beta=\langle\beta\rangle \pm 2 u_{c}(\beta),
$$

where $\langle\beta\rangle$ is a mean value calculated by (5) using mean values from Tab. 1. After substituting these numerical values, we obtain $\beta=12.85 \pm 0.58 \mathrm{~m}^{-1}$, ie a relative expanded uncertainty of the geometrical factor is $\sim 4.5 \%$.

\subsection{Uncertainty analysis of the electrical con- ductivity}

The conductivity is calculated from (1), in which the value $\beta=12.85 \mathrm{~m}^{-1}$ is substituted. The only values that are measured directly are the current $I$ and voltage $U$. Their mean values, standard deviations and uncertainties are given in Tab. 3. The source of the voltage was stabilized and no fluctuation of this quantity was observed. The sensitivity coefficients derived from (1) by partial derivations are

$$
A(\beta)=\frac{I}{U}, \quad A(I)=\frac{\beta}{U}, \quad A(U)=-\beta \frac{I}{U^{2}} .
$$

The numerical values of these coefficients are given in Tab. 4. 
Table 4. List of uncertainties for electrical conductivity

\begin{tabular}{|c|c|c|c|c|c|}
\hline & $\begin{array}{l}\text { Uncertainity } \\
\text { source }\end{array}$ & Type & $\begin{array}{l}\text { sensitivity } \\
\text { coefficient } A\end{array}$ & $\begin{array}{c}\text { standard } \\
\text { uncertainity } u(x)\end{array}$ & $\begin{array}{c}A(u)(x) \\
\left(\Omega^{-1} \mathrm{~m}^{-1}\right)\end{array}$ \\
\hline 1 & Repeatibility of $I$ & $\mathrm{~A}$ & $2.67 \mathrm{~m}^{-1} \mathrm{~V}^{-1}$ & $3.00 \times 10^{-8} \mathrm{~A}$ & $8.00 \times 10^{-8}$ \\
\hline$\underline{2}$ & Repeatibility of $U$ & $\mathrm{~A}$ & $-8.62 \times 10^{-7} \mathrm{~m}^{-1} \mathrm{~V}^{-2} \mathrm{~A}$ & 0 & 0 \\
\hline \multicolumn{5}{|c|}{ The sum of the A-type uncertainties } & $8.00 \times 10^{-8}$ \\
\hline 3 & $\begin{array}{l}\text { V-meter, } M A E=1 \times 10^{-5} \mathrm{~V} \\
u_{B}(U)=1 \times 10^{-5} / \sqrt{3}\end{array}$ & $\mathrm{~B}$ & $-8.62 \times 10^{-7} \mathrm{~m}^{-1} \mathrm{~V}^{-2} \mathrm{~A}$ & $5.77 \times 10^{-6} \mathrm{~V}$ & $-4.97 \times 10^{-12}$ \\
\hline 4 & $\begin{array}{l}\text { Electromet. } M A E=1 \times 10^{-12} \mathrm{~A} \\
u_{B}(I)=1 \times 10^{-12} / \sqrt{3}\end{array}$ & $\mathrm{~B}$ & $2.67 \mathrm{~m}^{-1} \mathrm{~V}^{-1}$ & $5.77 \times 10^{-13} \mathrm{~A}$ & $1.54 \times 10^{-12}$ \\
\hline & Geometrical factor & $\mathrm{B}$ & $3.23 \times 10^{-7} \mathrm{AV}^{-1}$ & $0.58 \mathrm{~m}^{-1}$ & $1.87 \times 10^{-7}$ \\
\hline & Measuring regime & $\mathrm{B}$ & $2.67 \mathrm{~m}^{-1} \mathrm{~V}^{-1}$ & $4 \times 10^{-8} \mathrm{~A}$ & $1.06 \times 10^{-7}$ \\
\hline 6 & Influence of drying & $\mathrm{B}$ & $2.67 \mathrm{~m}^{-1} \mathrm{~V}^{-1}$ & $1 \times 10^{-8} \mathrm{~A}$ & $2.67 \times 10^{-8}$ \\
\hline 6 & Thermal expansion & $\mathrm{B}$ & $2.67 \mathrm{~m}^{-1} \mathrm{~V}^{-1}$ & $7 \times 10^{-9} \mathrm{~A}$ & $1.87 \times 10^{-8}$ \\
\hline \multirow{3}{*}{\multicolumn{5}{|c|}{$\begin{array}{c}\text { The sum of the B-type uncertainties, (12) } \\
\text { The combined uncertainty, (13) } \\
\text { The expanded uncertainty }\end{array}$}} & $2.17 \times 10^{-7}$ \\
\hline & & & & & $2.31 \times 10^{-7}$ \\
\hline & & & & & $4.62 \times 10^{-7}$ \\
\hline
\end{tabular}

The type $\mathrm{B}$ uncertainties, which are related to the measurers, are showed in Tab. 4 , lines 3 and 4 . The next uncertainties have different sources and are evaluated individually.

The influence of inhomogeneity of the temperature field. When the temperature is not distributed uniformly along the sample, its properties become a function of the location. In addition to that, when the electrodes are under different temperatures, thermodiffusion current occurs [6]. Therefore a homogeneous temperature field is required. An inner space of the furnace has dimensions $10 \times 12 \times 12 \mathrm{~cm}$ which is much bigger than the sample dimensions $1 \times 1 \times 2 \mathrm{~cm}$. The sample is located in the center of the furnace where the space of the homogeneous temperature is $\sim 8 \times 4 \times 4 \mathrm{~cm}$, at the temperature of $1000^{\circ} \mathrm{C}$. Therefore, we consider that the sample is in the homogeneous temperature field and no temperature gradients are in the sample.

The influence of the measuring regime. As noticed above, the measuring period, which is $20 \mathrm{~s}$ long, consists from $16 \mathrm{~s}$ long time when the furnace is switched on and $4 \mathrm{~s}$ long time when the furnace is switched off. During this time, the current is measured. The temperature of the air in the furnace falls down by $6{ }^{\circ} \mathrm{C}$ in $4 \mathrm{~s}$ at $1000{ }^{\circ} \mathrm{C}$. According to Fig. 4, the electrical current is changed by $0.06 \mu \mathrm{A}$. However, due to a thermal inertia of the sample, the sample temperature changes less than $6{ }^{\circ} \mathrm{C}$, and the current also changes to a lesser extent, say $0.04 \mu \mathrm{A}$.

The overlap of electrodes. The sample is designed with the overlap of the wire electrodes $15 \mathrm{~mm}$. We experimentally found that a deviation of the overlap in the range between 14 and $20 \mathrm{~mm}$ does not lead to a change of the current. Therefore, an inaccuracy of $\pm 0.5 \mathrm{~mm}$ in adjustment of $b$, which is easy to reach, does not influence the current.

Corrosion of the electrodes. We tested electrodes from $\mathrm{Cu}$ and kanthal and found that they are not suitable for higher temperatures. Therefore we used platinum electrodes as we did in our previous research $[1-3,4]$ and as was used in $[5,8]$ and recommended in [10]. We did not observe a corrosion of the $\mathrm{Pt}$ wires (electrodes) and, consequently, did not consider influence of corrosion on the current measurement.

The influence of the drying. The sample was prepared from the plastic clay mass that contains $\sim 20 w t \%$ of the water. The sample has shorter dimensions after drying; consequently, the distance between the wire electrodes also gets shorter. According to Bigot's line for kaolin [14], the distance between the wire electrodes, which was adjusted to $3 \mathrm{~mm}$ when the sample was wet, shrinks by $3.4 \%$, ie $0.1 \mathrm{~mm}$. This leads to an increase of the current. We used a formula for capacity that is between two cylindrical electrodes of the radius $r$ with a distance $a$ between them, which pass through an infinite plate of the thickness $b[16]$. The analogy between an electrostatic field and current field allows us to derive a conductivity of the material according to a formula

$$
\sigma=\frac{1}{\pi b} \ln \left(\frac{a}{2 r}+\sqrt{\frac{a^{2}}{4 r^{2}}-1}\right) \frac{I}{U}
$$

Using (11) we can roughly estimate a change of the current $I$ when the distance $a$ changes by $0.1 \mathrm{~mm}$. We obtained $\sim 0.01 \mu \mathrm{A}$.

The influence of the thermal expansion. As follows from Fig. 2, the sample changes its dimensions during heating. Let us estimate this influence at $1000^{\circ} \mathrm{C}$ where the thermal contraction reaches the highest value (Fig. 2). The distance between the electrodes is shorter by $2.2 \%$, ie $0.065 \mathrm{~mm}$. It also leads to an increase of the current. Using (11) we estimated this increase as $\sim 0.007 \mu \mathrm{A}$ at $1000^{\circ} \mathrm{C}$.

The B-type of the uncertainty is

$$
\begin{array}{r}
u_{B}(\sigma)=\left(A^{2}(U) u_{B}^{2}(U)+A^{2}(I) u_{B}^{2}(I)+A^{2}(\beta) u_{B}^{2}(\beta)\right. \\
\left.+\sum_{i=1}^{3} A^{2}(I) u_{B}^{2}\left(x_{i}\right)\right)^{1 / 2}
\end{array}
$$


The first two terms come from the MAE of the measurers, the third term is the uncertainty of the geometrical factor and the fourth term represents a sum of three uncertainties that are in lines 6,7 and 8 in Tab. 4 .

The combined uncertainty of the conductivity is

$$
u_{c}(\sigma)=\sqrt{u_{A}^{2}(\sigma)+u_{B}^{2}(\sigma)}
$$

and the expanded uncertainty is $2 u_{c}(\sigma)$.

The current through the sample is $2.66 \mu \mathrm{A}$ at $1000^{\circ} \mathrm{C}$, the voltage $U=4.82 \mathrm{~V}$, so we obtain from (1) that the conductivity at $1000{ }^{\circ} \mathrm{C}$ is $7.09 \times 10^{-6} \Omega^{-1} \mathrm{~m}^{-1}$. The combined uncertainty is $4.62 \times 10^{-7} \Omega^{-1} \mathrm{~m}^{-1}$ (see Tab. 4), which means that we determine the conductivity with a relative uncertainty $\sim 6.5 \%$. Since the sample dimensions change during heating, this uncertainty varies with a temperature but not exceeds $6.5 \%$.

\section{CONCLUSIONS}

The electrical DC conductivity was measured at room and elevated temperatures on green ceramic samples prepared from kaolin. The used arrangement of the sample with two platinum wire electrodes inserted in the kaolin prism is suitable for measurements of temperature dependences of the conductivity from $20^{\circ} \mathrm{C}$ to $1100{ }^{\circ} \mathrm{C}$ in the air.

A description of the experimental arrangement from the point of view of possible sources of uncertainties is given. The uncertainty analysis taking into account thermal expansion of the sample, homogeneity of the temperature field, measurement regime, the corrosion of the electrodes and overlapping of the electrodes is done for $1000{ }^{\circ} \mathrm{C}$. Uncertainties connected with current and voltage measurements and uncertainties connected with instruments used are also considered. The sum of all the partial uncertainties gives an expanded uncertainty of the conductivity measurement. The uncertainty varies with temperature and reaches the highest value, $\sim 6.5 \%$, at $1000^{\circ} \mathrm{C}$.

\section{Acknowledgement}

This work has been supported by the grant VEGA $1 / 0464 / 12$. The authors are indebted to ceramic plant PPC Insulators Čab, Slovakia for a supply of kaolin. The authors are indebted to K. Mitterpach for technical help.

\section{REFERENCES}

[1] ŠTUBŇA, I.-KOZÍK, T.: Electric Conductivity of Kaolin in the Temperature Range $150-560{ }^{\circ} \mathrm{C}$, Journal of Thermal Analysis 46 (1996), 607-610.

[2] TRNovCOVÁ, V.-PODOBA, R.-ŠTUBŇA, I. : DC Conductivity of Kaolin-Based Ceramics in the Temperature Range 20-600 ${ }^{\circ} \mathrm{C}$, Épitőanyag - Building Materials 64 (2012), 52-55.

[3] TRNOvCOVÁ, V.-FURÁR, I.-HANIC, F.: Influence of Technological Texture on Electrical Properties of Industrial Ceramics, J. of Physics and Chemistry of Solids 68 (2007), 1135-1139.

[4] PODOBA, R.-ŠTUBŇA, I.-TRNOVCOVÁ, V.-TRNÍK, A.: Temperature Dependence of DC Electrical Conductivity of Kaolin, J. Thermal Analysis and Calorimetry vol118 (2013), 567-601.

[5] SHEIKH-ZADE, R. M.: Study of Kaolin Sintering by an Electric Conductivity Method, Ogneupory No. 1 (1972), 21-23.

[6] ORESHKIN, P. T.: Electrical Conductivity of Refractories, Metallurgia, Moskva, 1965. (in Russian)

[7] BOGORODICKIJ, N. P.-PASYNKOV, V. V.-TAREEV, B. M.: Electrotechnical Materials, Gosudarstvennoe energeticheskoe izdatelstvo, Moskva, 1963. (in Russian)

[8] MAITI, G. C.-FREUND, F.: Dehydratation-Related Proton Conductivity in Kaolinite, Clay Minerals 16 (1981), 395-413.

[9] Blumenthal, R. N.-SEITZ, M. A.: Experimental Techniques, In: Electrical Conductivity in Ceramics and Glass, part A. (N.M. Tallan, eds.), Marcel Dekker Inc., New York, 1974.

[10] Kohlrausch praktische Physik 3, Teubner Verlag, Stuttgart, 1968.

[11] PTÁČEK, P.—ŠOUKAL, F.-OPRAVIL, T.-NOSKOVÁ, M.-HAVLICA, J.-BRANDŠTETR, J.: Crystallization of Spinel Phase from Metakaoline: The Nonisothermal Thermodilatometric CRH Study, Powder Technology 243 (2013), 40-45.

[12] PTÁČEK, P.—KREČKOVÁ, M.—ŠOUKAL, F.—OPRAVILL, T.-HAVLICA, J.-BRANŠDŠTETR, J.: The Kinetics and Mechanism of Kaolin Powder Sintering I. The Dilatometric CRH Study of Sinter-Crystallization of mullite and Cristobalite, Powder Technology 232 (2012), 24-30.

[13] BROŽ, J.et al: The Fundamentals of Physical Measurement, SPN, Praha, 1967. (in Czech)

[14] PODOBA, R.-ŠTUBŇA, I.-VOZÁR, L. : A.C. Conductivity of Wet Green Electroporcelain Mixture, In: Proc. of the Conf. 25. DIDMATTECH 2012, Selye University, Komárno, 2012, pp. 35-41.

[15] Evaluation of Measurement Data - Guide to the Expression of Uncertainty in Measurement, Joint Committee for Guides in Metrology, Sévres Cedex 2010.

[16] MYSLÍK, J.: Electromagnetic Field - a Basic Theory, Technická literatura BEN, Praha 1998. (in Czech)

Received 15 May 2014

Igor Štubňa, Viera Trnovcová, Libor Vozár, Štefan Csáki - biographies not supplied. 